\title{
COMPREHENSIVE REVIEW ON HEART DISEASE PREDICTION USING OPTIMIZATION TECHNIQUES
}

\author{
S.Saranya ${ }^{1}$ \\ ${ }^{1}$ Research Scholar \& Assistant Professor, Department of Computer Applications, Hindusthan \\ College of Arts and Science, Coimbatore. \\ P.Deepika ${ }^{2}$ \\ ${ }^{2}$ Research Scholar \& Assistant Professor, PG \& Research Department of Computer Science, \\ Hindusthan College of Arts and Science, Coimbatore. \\ Dr.S.Sasikala ${ }^{3}$ \\ ${ }^{3}$ Associate Professor, Department of Computer Applications, Hindusthan College of Arts and \\ Science, Coimbatore
}

Article DOI URL: https://doi.org/10.36713/epra3887

\begin{abstract}
Heart disease is one of the main sources of demise around the world. It is imperative to predict the disease at a premature phase. The computer aided systems help the doctor as a tool for predicting and diagnosing heart attack. This research mainly focuses on the study of women heart attack prediction are analysed. Heart disease is the leading cause of death for both men and women. The early symptoms of heart attack can be quite different from men \& women. It is a common belief that women are better at looking their health than men. But when it comes to heart health, research shows that many women don't and often put the needs of others before themselves. In this study we studied various available techniques and diagnosis of heart attack disease with a sophisticated approach to data extraction, the Ant Colony Optimization technique.
\end{abstract}

KEYWORDS: data mining, Heart disease, Ant colony optimization, pheromone

\section{INTRODUCTION}

Heart disease is one in all the most sources of ending round the world. It's imperative to predict the difficulty at a premature section. The pc assisted systems facilitate the doctor as a tool for predicting and designation heart attack. This analysis chiefly focuses on the study of ladies heartfailure prediction are analysed. Cardiovasc ular disease is that the leading reason for death for each men and ladies. The first symptoms of heart failure will be quite completely different from men \& women. It's a typical belief that women are higher at wanting their health than men. However once it involves heart health, analysis shows that a lot of women's don't and sometimes place the requirements of others before themselves. This paper has focused on Data mining method and technology to change this information into useful data for conclusion. The data mining algorithms will helps to produce the outcome in fast prediction of disease with high accuracy. This study focusedon numerous accessible techniques and designation of heartfailure problem with acompli cated approach to information extraction, the ant Colony improvement technique.

Health care data is the collection and consumption of information from all aspects of fitness and it has the target of analysing the patient what will happen for them in a manner as a both efficient and accurate. The final target for the health data is the quality of concern that the health care field can provide to the patients. Research can apply the 


\section{EPRA International Journal of Research and Development (IJRD)}

Volume: 5 | Issue: 1 | January 2020

data mining and investigative the medical information in order to develop a innovative ways of making the conclusion faster and efficient and it will be more accurate and its cost effective than existing procedure. The unconsumed information has been changed to beneficial data with the help of various data mining techniques.

In the present world, Cardiovascular Disease (CVD) is the highly increasing disease. CVD is disorders of the heart and the blood vessels and it have been included of heart disease, Cerebrovascular disease, rheumatic heart disease. Many human deaths in recent are due to the heart attacks and strokes. CVD can exhibit blood pressure, glucose, and lipids and mainly for the youngsters due to the overweight and obesity. A good quality life style and the premature detection is the way for preventing the heart disease. This early detection can be done with the help of computer the use of the computer is able to present the health check improvements. In modern world, the recognition of the disease can be easily done by the medical expert abilities with the basic current test results. To make a diagnose of the disease is so critical task that needs high skills and a great deal knowledge. The mainly focusing for detecting the disease with the help of data mining techniques. Machine learning makes it achievable to obtain the information from a enormous data, it's impossible for the human.

\section{MACHINE LEARNING TECHNIQUES \\ ANT COLONY OPTIMIZATION(ACO):}

The ant colony algorithm is for discovery the best paths and that is based on the performance of ants searching for food. Ants will communicate their information to other ant by leaving "markers" (pheromones). Those pheromones show the path for the food. The others have moving on the way of the markers they will likely to follow the path of the pheromones with a high probability. If the ants do the same then they populate the pathway with help of their own Pheromones as they bring the food back faster. Then the others ants are also find the path, it will gets much stronger till there are a pair of streams of ants were progress to the different food sources close to the colony.

Ant behaviour is shown in Figure below using random moves and the markers (pheromones) within a land containing one nest and one food source, the ants will go away from the nest, discover the food and return to the nest. After some time, the path being used by the ants will be converging to the shortest way.

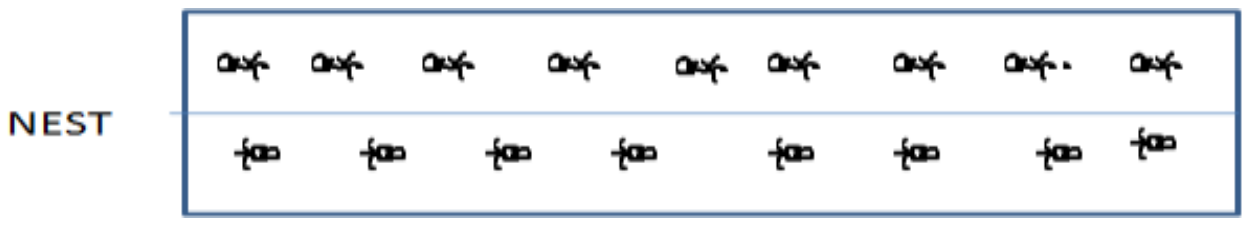

FIGURE1. Ants in a pheromone trail between nest and food

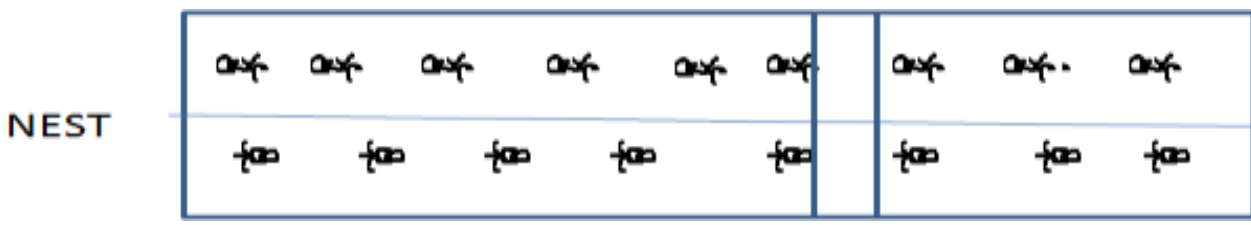

FIGURE2. An obstacle interrupts the trail

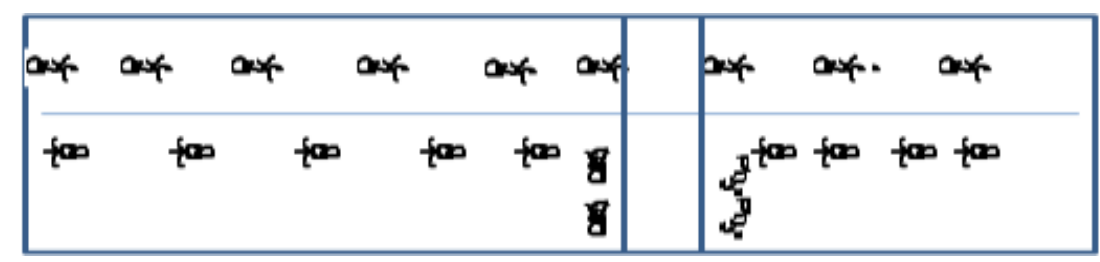

FOOD SOURCE

FIGURE 3. Ants find two paths to go around the obstacle] 


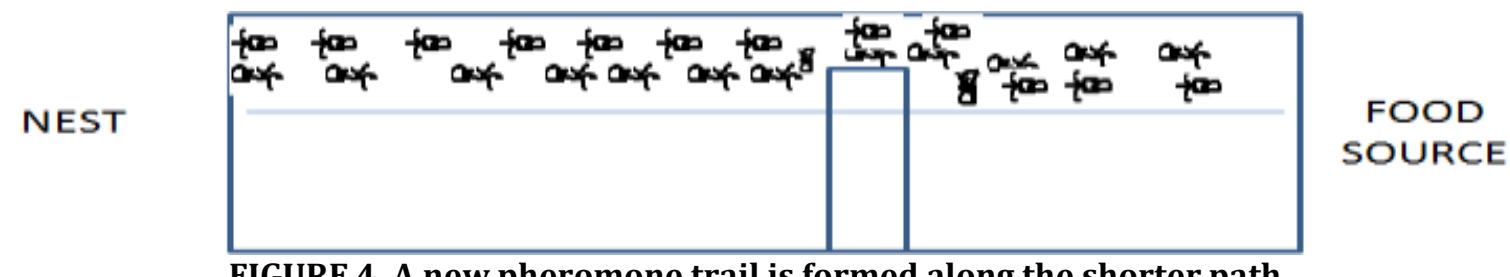

FIGURE 4. A new pheromone trail is formed along the shorter path.

The ACO algorithm is based on extensible altering the pheromone on the path at each node shown in following figure. The selection of this node is leads to a probability based selection approach.

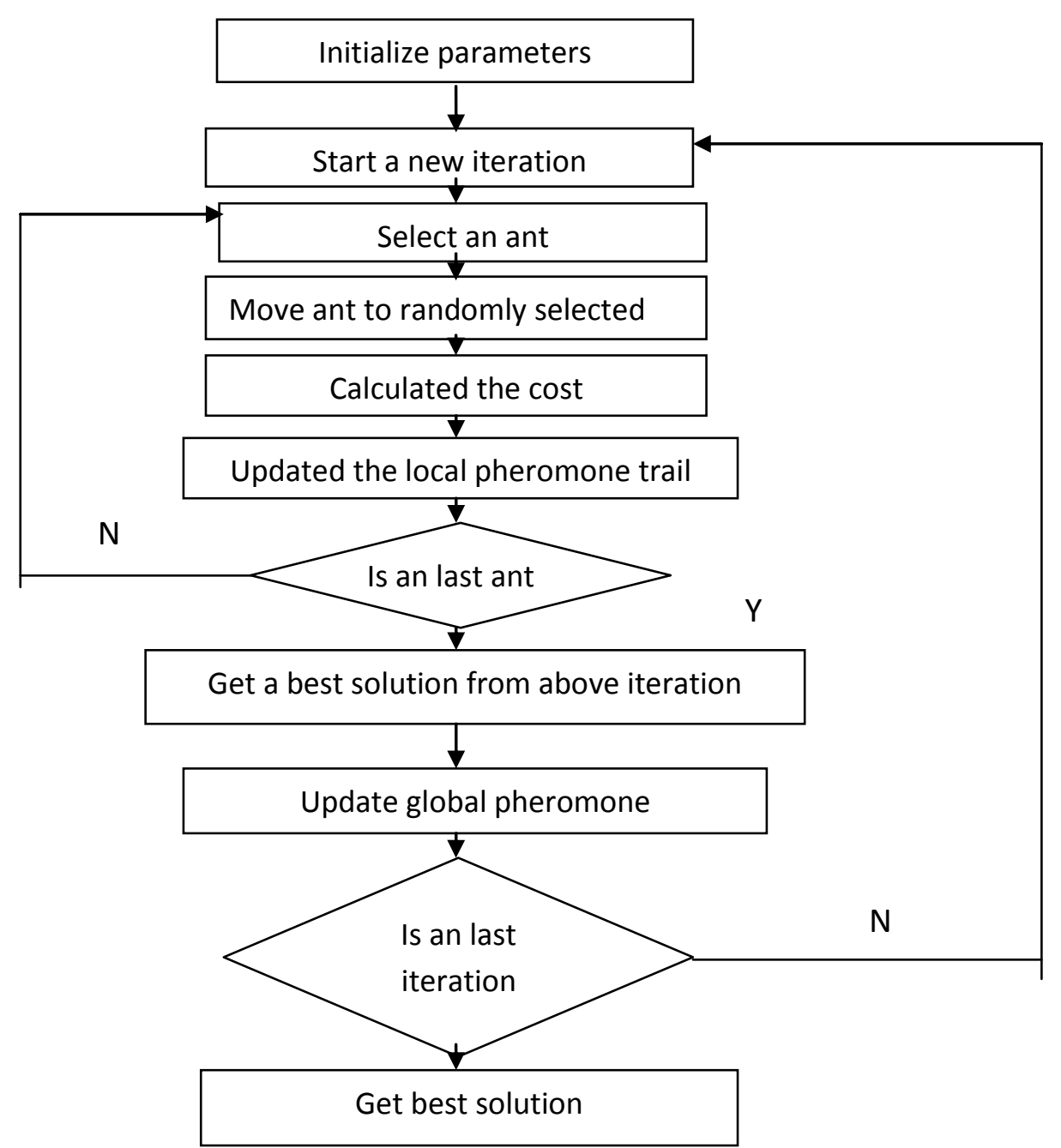

\section{EXISTING LITERATURE}

Poonam Kataria, parag et al [1], present work has been implemented method using PSO based classification and it has been successfully using UCI Repository of Machine Learning Databases. The goal of classification is to attain improved classification using data set of diabetic patients for discovery of diabetes. The results has proven that the accuracy generated by using particle swarm optimization(PSO) is more as compare to other optimization algorithms named as genetic algorithm and ant colony optimization algorithm(ACO) in classification process.

Rafael S. Parpinelli, parag et al [2], they have been proposed an algorithm for rule discovery called Ant-Miner. The aim of Ant-Miner is to find out 


\section{SJIF Impact Factor: 6.260| ISI I.F.Value:1.241| Journal DOI: 10.36713/epra2016 ISSN: 2455-7838(Online) EPRA International Journal of Research and Development (IJRD)}

classification rules in the data sets. The algorithm is based both on investigate on the behaviour of real ant colonies and on data-mining concepts and ethics. They have been compared the performance of AntMiner and the well-known CN2 algorithm in six public domain data sets. The conclusion the results proved that, concerning predictive accuracy and the rule lists has been exposed by Ant-Miner are considerably simpler than those exposed by CN2.

Pise Satish Prakashra, parag et al [3], the study has determined on the formulation and implementation of an better and reliable model for the analysis of heart attack disease with a sophisticated approach to information extraction, using the Ant Colony Optimization technique(ACO). They have first generated the support, symptom weight, which will be the initial value of the pheromone. There are different types of heart disease that can be considered here as Congenital Heart Disease, Congestive Heart Failure, Coronary Heart Disease. Based on this they have finding the risk and identify the maximum value of the pheromone and the maximum value of the pheromone is the addition of weight and risk level. The ant has to find out the maximum value of the pheromone, as the sensitive ant movements and the ratio of the symptoms will modify. According to these techniques, the number of fragments can be managed via the ACO parameter. They has proven the higher recognition accuracy.

"Parag Deoskar and Dr. Divakar Singh, parag et al [4], An Efficient Support Based Ant Colony Optimization Technique for Lung Cancer Data, they have been proposed a new algorithm that is support based ant colony optimization technique (SPACO). This algorithm is generally separated into three types, first type they accept the data set of cancer symptoms which is a generalized a system for creating the patterns for Lung Cancer Framework, second type find the relevant information from the patterns. At this stage picks up the repeated symptoms only by using the support count value. Depending on the support value then decide the ants and pheromone value. By initialize the pheromone value which is the sustain of the pattern for the cancer symptoms. It will update in each trial. By updating the pheromone value in each step now check the symptom quality which either increases the prediction or decreases the prediction. In result analysis they have been the effectiveness of our algorithm.

"Youness Khourdifi1, Mohamed Bahaj1"[5], Heart Disease Prediction and Classification Using Machine Learning Algorithms Optimized by Particle Swarm Optimization and Ant Colony Optimization, The proposed work has been applied to heart disease dataset, the results has exhibit the efficacy and robustness of the proposed hybrid system in processing different types of data for heart disease classification. The research has been observe the different machine learning algorithms and compares the results using diverse performance measures, i.e. accuracy, precision, recall, fl-score, etc. A highest classification accuracy of $99.65 \%$ using the optimized model proposed by FCBF, PSO and ACO. The results proven the performance of the proposed system is superior to that of the classification method

"Wei Gao" [6], Improved Ant Colony Clustering Algorithm and Its Performance Study, A new abstraction ant colony clustering algorithm using a information combination method has proposed to progress the computational efficiency and accuracy of the ant colony clustering algorithm. The concept of ant colony clustering algorithm is used to cluster benchmark trouble, and its performance is compared with the ant colony clustering algorithm and other techniques has used in existing literature. According to the similar computational problems and complexities, the results illustrate that the concept of ant colony clustering algorithm produces the results that it was not more accurate but also more efficiently resolute than the ant colony clustering algorithm and the other techniques. so, the concept of ant colony clustering algorithm can be used for efficient multivariate data clustering. 


\section{EPRA International Journal of Research and Development (IJRD) \\ Volume: 5 | Issue: 1 | January 2020 \\ - Peer Reviewed Journal}

\section{INFERENCES FROM EXISTING STUDY}

\begin{tabular}{|c|c|c|c|c|}
\hline Author & Year & Purpose & Techniques used & Accuracy \\
\hline $\begin{array}{c}\text { Poonam Kataria, } \\
\text { Navpreet Rupal, } \\
\text { Rahul Sharma }\end{array}$ & 2014 & $\begin{array}{l}\text { comparative study of GA, } \\
\text { ACO \& PSO based Data } \\
\text { Clustering methods. }\end{array}$ & GA, ACO \& PSO & $\begin{array}{c}\text { particle swarm } \\
\text { optimization } \\
\text { techniques results as } \\
\text { the best optimization } \\
\text { technique } \\
\end{array}$ \\
\hline $\begin{array}{l}\text { Rafael S. Parpinelli, } \\
\text { Heitor S. Lopes, and } \\
\text { Alex A. Freitas }\end{array}$ & 2002 & $\begin{array}{l}\text { compare the } \\
\text { performance of Ant- } \\
\text { Minerwith CN2. } \\
\text { To discover classification } \\
\text { rules in data sets. }\end{array}$ & ACO \& New ACO & $\begin{array}{c}\text { Ant-Miner has } \\
\text { consistently found } \\
\text { much simpler } \\
\text { (smaller) rule lists } \\
\text { than CN2 }\end{array}$ \\
\hline $\begin{array}{c}\text { Pise Satish } \\
\text { Prakashrao, Anoop } \\
\text { Singh \& Ritesh } \\
\text { Kumar Yadav }\end{array}$ & 2018 & $\begin{array}{l}\text { Improved and reliable } \\
\text { model for the diagnosis } \\
\text { of heart attack disease }\end{array}$ & $\begin{array}{l}\text { ACO and K-Means } \\
\text { Algorithm }\end{array}$ & $\begin{array}{l}\text { Achieved higher } \\
\text { recognition accuracy }\end{array}$ \\
\hline $\begin{array}{l}\text { Parag Deoskar, Dr. } \\
\text { Divakar Singh, Dr. } \\
\text { Anju Sing }\end{array}$ & 2013 & $\begin{array}{l}\text { They present an effective } \\
\text { approach which is based } \\
\text { on association and } \\
\text { optimization for lung } \\
\text { cancer prediction. }\end{array}$ & SPACO,ACO & $\begin{array}{l}\text { Result analysis, has } \\
\text { proved the } \\
\text { effectiveness of SPACO } \\
\text { algorithm }\end{array}$ \\
\hline $\begin{array}{l}\text { Youness Khourdifi, } \\
\text { Mohamed Bahaj }\end{array}$ & 2018 & $\begin{array}{c}\text { Exploited the Fast } \\
\text { Correlation-Based } \\
\text { Feature Selection (FCBF) } \\
\text { method to filter } \\
\text { redundant features in } \\
\text { order to improve the } \\
\text { quality of heart disease } \\
\text { classification. } \\
\text { compare algorithms with } \\
\text { different performance } \\
\text { measures using machine } \\
\text { learning }\end{array}$ & ACO,PSO & $\begin{array}{l}\text { The performance of } \\
\text { the proposed system } \\
\text { is superior to that of } \\
\text { the classification } \\
\text { technique }\end{array}$ \\
\hline Wei Gao & 2016 & $\begin{array}{l}\text { A new abstraction ant } \\
\text { colony clustering } \\
\text { algorithm using a data } \\
\text { combination mechanism } \\
\text { is proposed to improve } \\
\text { the computational } \\
\text { efficiency and accuracy of } \\
\text { the ant colony clustering } \\
\text { algorithm }\end{array}$ & $\begin{array}{c}\text { ACO, Abstraction } \\
\text { ACO }\end{array}$ & $\begin{array}{l}\text { The abstraction ant } \\
\text { colony clustering } \\
\text { algorithm produces } \\
\text { results that are not } \\
\text { only more accurate } \\
\text { but also more } \\
\text { efficiently determined } \\
\text { than the ant colony } \\
\text { clustering algorithm } \\
\text { and the other } \\
\text { methods. } \\
\text { The abstraction ant } \\
\text { colony clustering } \\
\text { algorithm can be used } \\
\text { for efficient } \\
\text { multivariate data } \\
\text { clustering. }\end{array}$ \\
\hline
\end{tabular}

2020 EPRA IJRD | Journal DOI: https://doi.org/10.36713/epra2016 | www.eprajournals.com |11 | 


\section{SJIF Impact Factor: 6.260| ISI I.F.Value:1.241| Journal DOI: 10.36713/epra2016 ISSN: 2455-7838(Online) EPRA International Journal of Research and Development (IJRD)}

\section{CONCLUSION}

Heart disease prediction is not easy and very significant in the medical field. It's complicated to recognize the heart disease since there are several con-tributory risk factors such as diabetes, blood pressure, cholesterol, abnormal pulse rate and numerous factors. Different techniques in data mining have been engaged to find out the harshness of heart disease among humans. The goal of the paper is to provide an insight of heart disease risk analysis using ACO.

\section{REFERENCES}

1. Poonam Kataria, Navpreet Rupal, Rahul Sharma, "Comparative Analysis of Clustering by using Optimization Algorithms" International Jounarl of Computer Science and Information Technologies, Volume-5, Issue-2, 2014.

2. Rafael S. Parpinelli, Heitor S. Lopes, Member, IEEE, and Alex A. Freitas, "Data Mining With an Ant Colony Optimization Algorithm", IEEE TRANSACTIONS ON EVOLUTIONARY COMPUTING, VOL. 6, NO. 4, AUGUST 2002

3. Pise Satish Prakashrao, Anoop Sing, Ritesh Kumar Yadav,"An efficient approach for detection of heart attack using noble ant colony optimization concept of data mining", International Journal of Engineering Sciences \& Research Technology [IJESRT, Feb 2018

4. Parag Deoskar, Dr. Divakar Singh, Dr. Anju Singh, "An Efficient Support Based Ant Colony Optimization Technique for Lung Cancer Data”, International Journal of Advanced Research in Computer and Communication Engineering Vol. 2, Issue 9, September 2013

5. "Youness Khourdifi, Mohamed Bahaj, "Heart Disease Prediction and Classification Using Machine Learning Algorithms Optimized by Particle Swarm Optimization and Ant Colony Optimization", International Journal of Intelligent Engineering and Systems, Vol.12, No.1, 2019

6. Wei Gao , "Improved Ant Colony Clustering Algorithm and Its Performance Study", Hindawi Publishing Corporation Computational Intelligence and Neuroscience Volume 2016, Article ID 4835932, 14 pages, September 2005
7. M.N. Sohail, Ren Jiadong, M. Irshad, M.M. Uba, S.I. Abir, "Data mining techniques for Medical Growth: A Contribution of Researcher reviews", IJCSNS International Journal of Computer Science and Network Security, VOL.18 No.10, October 2018

8. Dr. B. Umadevi, M. Snehapriya," A Survey on Prediction of Heart Disease Using Data Mining Techniques", International Journal of Science and Research (IJSR) ISSN (Online): 2319-7064, April 2017

9. K.Lokanayaki, A.Malathi," Exploring on Various Prediction Model in Data Mining Techniques for Disease Diagnosis", International Journal of Computer Applications , Volume 77 - No.5, September 2013

10. V.V. Ramalingam,Ayantan Dandapath, M Karthik Raja, "Heart disease prediction using machine learning techniques: a survey”, International Journal of Engineering \& Technology

11. Zoubida Alaoui Mdaghri, Mourad El Yadari, Abdelillah Benyoussef, Abdellah El Kenz," Study and analysis of data mining for healthcare ", 2016 4th IEEE International Colloquium on Information Science and Technology (CiSt)

12. Aditi Gavhane, Gouthami Kokkula, Isha Pandya, Prof. Kailas Devadkar," Prediction of Heart Disease Using Machine Learning", Proceedings of the 2nd International conference on Electronics, Communication and Aerospace Technology (ICECA 2018) IEEE Conference Record \# 42487; IEEE Xplore ISBN:978-15386-0965-1

13. .Dinesh Kumar G, Santhosh Kumar D, Arumugaraj K, Mareeswari V," Prediction of Cardiovascular Disease Using Machine Learning Algorithms", Proceeding of 2018 IEEE International Conference on Current Trends toward Converging Technologies, Coimbatore, India.

14. K.Thenmozhi, P.Deepika," Heart Disease Prediction using classification with different Decision Tree Techniques" International Journal of Engineering Research and General Science, Vol-2, Issue-6, 2014.

15. K.Thenmozhi, P.Deepika, M.Meiyappasamy, " Different Data Mining Techniques involved in Heart Disease Prediction" International Journal of Scientific Research, Volume-3, Issue-9, 2014. 
16. P.Deepika, P.Vinothini, “ Heart Disease Analysis and Prediction Using Various Classification Models- A Survey" PARIPEXIndian Journal of Research, Volume-3, Issue-4, 2015.

17. P.Deepika, A.Kiruthika, S.Saranya, Dr.S.Sasikala, “ A Novel Classification and Prediction Algorithm for Heart Disease Identification" International Journal of Engineering Science Invention, Vloume-7, Issue-2, 2018.

18. P.Deepika, S.Saranya, Dr.S.Sasikala," An Effective Archetype design of Heart Disease Anticipation Using Optimization Techniques" EPRA - International Journal of Research and Development, Volume-4, Issue-11, 2019.

19. P.Deepika, S.Saranya, Dr.S.Sasikala, "The Study of Fuzzy Cognitive Maps in Identification and Prediction of Diseases" IOSR Journal of Engineering, Volume-6, 2018.

20. P.Deepika, S.Saranya, A.Kiruthika, Dr.S.Sasikala, Dr.S.Jansi," Anticipating Heart Disease Using C4.5 Classification Augmented with Feature Selection" International Journal of Research \& Development in Technology, Volume-6, Issue-5, 2016.

21. A.Kiruthika, P.Deepika, Dr.S.Sasikala, S.Saranya, " Predicting Ailment of Thyroid Using Classification and Recital Indicators” International Journal of Scientific Research in Computer Science, Engineering and Information Technology, Volume-3, Issue-3, 2018.

22. S.Saranya, P.Deepika, Dr.S.Sasikala, Dr.S.Jansi, A.Kiruthika," Accelerating Unique Strategy for Centroid Priming in $K$ Means Clustering” International Journal for Innovative Research in Science \& Technology, Volume-3, Issue-7,2016.

23. S.Saranya, Dr.M.Punithavalli," An Effective Centroid Selection Algorithm for K-means Clustering" International Journal of Multidisciplinary Research Academy, Volume-1, Issue-3, 2014. 